\title{
Editorial
}

\section{Development and use of molecular markers for crop improvement}

Pushpendra K. Gupta ${ }^{1,4}, H_{a r i n d r a} \mathrm{~S}$. Balyan ${ }^{1}$, Rajeev K. Varshney ${ }^{2}$ and Kulvinder S. Gill ${ }^{3}$

${ }^{1}$ Department of Genetics \& Plant Breeding, Ch. Charan Singh University, Meerut, 250 004, U.P. India; ${ }^{2}$ Centre of Excellence in Genomics (CEG), International Crops Research Institute for the Semi-Arid Tropics (ICRISAT), Patancheru, 502 324, Greater Hyderabad, India; ${ }^{3}$ Department of Crop \& Soil Sciences, Washington State University, P.O. Box 646420, Pullman, WA 99164-6420, USA; ${ }^{4}$ Corresponding author, E-mail: pkgupta36@gmail.com

The global food production experienced a tremendous growth during the last 50 years, particularly following green revolution of the mid-1960s, which temporarily eased the problem of food security. However, the current food supplies are inadequate to meet the growing demand for food, posing a serious challenge to food and nutritional security (undernourishment and malnourishment), particularly in several underdeveloped and developing countries of Asia and Africa. During the last decade, acute spikes in food prices during 2007-08 and again in 2010-11 have witnessed food riots in urban Africa and many other parts of the world (Sneyd et al. 2013).

At the current rate of population growth, the global population is expected to touch at least 9 billion in 2050 (Godfray et al. 2010), putting an excessive pressure on the food, feed and fuel supply. To meet this challenge, food supply will need to grow annually by $2-3 \%$ (Hawkesford et al. 2013). In the past, global food production has largely been driven by the development of dwarf varieties that are responsive to high inputs (both water and fertilizers), which had negative impact on the environment leading to decline in crop yields and widening the gap between potential and realized yields. This has been further exacerbated by the yield losses of up to $40 \%$ due to the diseases and pests (Oerke 2006). Abiotic stresses such as drought (due to uncertain and irregular rains), heat (due to rise in temperature), salinity, mineral toxicities and nutrient deficiencies contribute to either decline in productivity or complete failure of crops.

To realize higher crop yields with minimum damage to the environment, it would be necessary to develop crop varieties with enhanced genetic yield potential through proper understanding of the genetic architecture of traits related to productivity, with enhanced resource utilization efficiency and tolerance to abiotic and biotic stresses. The recent genomic revolution including new generation high-throughput sequencing approaches has allowed the development of a battery of DNA-based molecular markers. Some of these molecular markers include simple sequence repeat (SSR), single-nucleotide polymorphism (SNP) and Diversity Array Technology (DArT), to name a few. These markers have been used in genetic mapping, gene tagging, QTL interval mapping, germplasm evaluation and molecular markerassisted selection (MAS) for the improvement of a number of important qualitative and quantitative traits in a variety of crop plants. Molecular breeding has thus attained a centre stage in crop improvement programmes, where it is being applied alone or in combination with conventional plant breeding methods, so as to bring more precision in the breeding programmes (Varshney et al. 2012).
To review and deliberate upon the developments in the area of molecular markers and their applications in crop improvement, an international symposium 'Development and Use of Molecular Markers for Crop Improvement' was organized during October 29-31, 2011 by the Department of Genetics \& Plant Breeding, Ch. Charan Singh University, Meerut, India, and the Washington State University, Pullman, USA. The symposium that was sponsored by Indo-US Science and Technology Forum, New Delhi, and supported by Ch. Charan Singh University, Meerut, and Monsanto India, Bangalore, was held at the National Agriculture Science Centre (NASC) Complex, DPS Road, New Delhi-110012. Nearly, 50 scientists from India, USA, Canada and Germany and an equal number of students participated in the symposium.

This Special Issue of Plant Breeding includes 11 articles based on the presentations made at the symposium. The lead article by Gurdev Singh Khush discusses the strategies of increasing yield potential of cereals (in particular rice). Another article deals with biofortification in cereals (Rawat et al.). The remaining nine articles are arranged cropwise such that two articles each are devoted to wheat (Balyan et al. and Randhawa et al.) and pigeonpea (Mir et al. and Saxena et al.), one each to rice (Singh et al.), foxtail millet (Lata and Prasad), maize (DeBruin et al.), Gossypium species (Srivastava et al.), and Brassica napus (Vengalat et al.). These articles discuss the application of molecular markers in wheat breeding, QTL analysis and improvement in grain protein content and other health-related constituents of wheat grain. The articles on pigeonpea discuss the association of molecular markers for important traits and also the production of world's first commercial food legume hybrid. Another article describes marker-assisted pyramiding of disease resistance genes in an elite basmati restorer line for the production of improved hybrid rice. The article on foxtail millet reports the validation of an allele-specific marker associated with dehydration stress tolerance. Another article discusses the distribution of nitrogen $(\mathrm{N})$ in different plant parts and its remobilization from leaf to grain to maximize grain yield in hybrid maize. The article on Gossypium species discusses the development of novel SSRs and SNPs enriching the available repertoire of molecular markers for use in genetic analysis and molecular breeding of cotton. A separate article discusses the genetic programmes that operate during embryo development in Brassica napus.

We hope the collection of articles dealing with the development and use of molecular markers in crop improvement will be useful to the researchers involved in crop breeding programmes 
aimed at improvement in productivity, quality and tolerance to biotic and abiotic stresses. This special issue should also prove useful as a reading material for teachers and students engaged in the study of genetics and plant breeding.

Acknowledgements: We sincerely acknowledge the help received from a large number of anonymous reviewers who spared their valuable time in reviewing the articles published in this special issue. Financial assistance was provided by the Indo-US Science and Technology Forum, New Delhi, Ch. Charan Singh University, Meerut, and the Monsanto India, Bangalore, for organizing the symposium on 'Development and Use of Molecular Markers for Crop Improvement'. Special thanks are due to Frank Ordon and Jens Léon (editors-in-chief) and Elsbeth Jung from the journal Plant Breeding for their kind help in the preparation of this Special Issue.

\section{References}

Godfray, H. C. J., J. R. Beddington, I. R. Crute, L. Haddad, D. Lawrence, J. F. Muir, J. Pretty, S. Robinson, S. M. Thomas, and C. Toulmin, 2010: Food security: the challenge of feeding 9 billion people. Science 327, 812-818.

Hawkesford, M. J., J. -L. Araus, R. Park, D. Calderini, D. Miralles, T. Shen, J. Zhang, and M. A. J. Parry, 2013: Prospects of doubling global wheat yields. Food Energy Security 2, 34-48.

Oerke, E. C., 2006: Crop losses to pests. J. Agric. Sci. 144, 31- 43.

Sneyd, L. Q., A. Legwegoh, and E. D. G. Fraser, 2013: Food riots: media perspectives on the causes of food protest in Africa. Food Security 5, 485-497.

Varshney, R. K., J. M. Ribaut, E. S. Buckler, R. Tuberosa, J. A. Rafalski, and P. Langridge, 2012: Can genomics boost productivity of orphan crops? Nat. Biotechnol. 30, 1172-1176. 